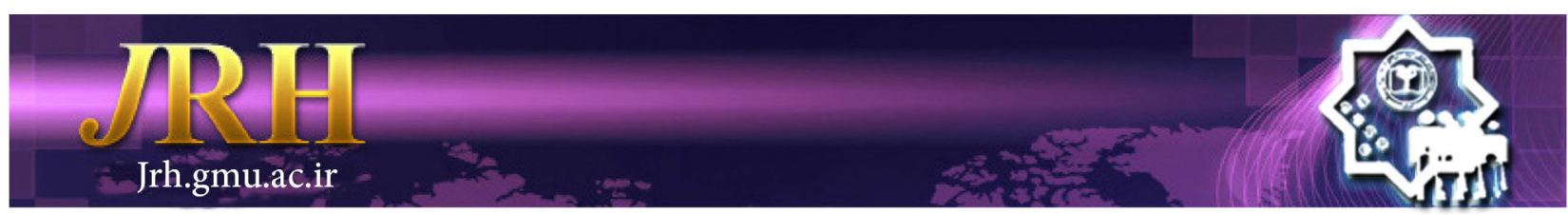

\title{
Comparing parental monitoring, affiliation with delinquent peers, and high-risk behaviors in single- parent and two-parent male adolescents
}

Shahriar Dargahi ${ }^{1}$, Ali Rezaei Sharif ${ }^{1}$, Javad Khodadadi Sangdeh², Masoud Nazari ${ }^{1}$, Zahra Bakhtiari ${ }^{2}$

\author{
Journal of Research \& Health \\ Social Development \& Health Promotion \\ Research Center \\ Vol. 8, No.5, Sep \& Oct 2018 \\ Pages: $411-417$ \\ DOI: $10.29252 / j r h .8 .5 .411$ \\ Original Article
}

1. Department of Counseling, Faculty of Psychology and Educational Sciences, University of Mohaghegh Ardabili, Ardabil, Iran 2. Department of Counseling, Faculty of Psychology and Educational Sciences, Kharazmi University, Tehran, Iran

Correspondence to: Zahra Bakhtiari, Department of Counseling, Faculty of Psychology and Educational Sciences, Kharazmi University, Tehran, Iran

Email: zahra.bakhtiari81@gmail.com

\section{Received: 5 Jun 2016}

Accepted: 17 Jan 2017

How to cite this article: Dargahi Sh, Rezaei Sharif A, Khodadadi Sangdeh J, Nazari M, Bakhtiari Z. Comparing parental monitoring, affiliation with delinquent peers, and highrisk behaviors in single-parent and two-parent male adolescents. $J$ Research \& Health2018; 8(5): 411- 417.

\begin{abstract}
Single-parent families maybe exposed of personal, interpersonal and family problems. Thus, the aim of the current research wasthe comparison of parental monitoring, affiliation with delinquent peers and high risk behaviors between single parent and two-parent adolescents. 100 single-parent adolescents and 100 two-parent adolescents in Eslamabad-e Gharb city of Kermanshah, Iran, were selected through Convenience sampling method, and responded to parental monitoring and affiliation with peers delinquent questionnaires and adolescent risk-taking scale. The results showed a significant difference between single parent and two-parent adolescent in terms of all three compared variables. Actually, single parent adolescents obtained lower score in parental monitoring and higher scores in affiliation with delinquent peers and high risk behaviors in comparison with twoparent adolescents. According to the results, it can be said that single-parent families are more exposed to problems. Therefore interventions to teach appropriate parenting style forparentsof single-parent adolescents and proper trainingsareessentialto prevent affiliation with delinquent peers and high risk behaviors among single-parent adolescents.
\end{abstract}

Keywords: Behaviors, Delinquency, High Risk, Peers, Single Parent

\section{Introduction}

The notion of family has long been consisted of man and woman that are married officially and/ or have a child or children. In contrast to this type of family, there issometimes a family, in which one of the parents is absent due to death or divorce, and the child or children live(s) with only one parent. Single parent is a title that many communities apply for these types of families. Most children in mother-headed families inevitably face many challenges, including problems due to the absence of father [1]. Children who have grown up in single-parent families have often behavioral problems because of problems at home. The individuals are more than twice susceptible to develop behavioral and psychological problems than those who grow up in healthy families [2]. The singleparent families possess unclear and vague boundaries and roles. In general, children of 
these families have academic and behavioral difficulties, and face a confused identity, which lead to an inability to communicate properly with the opposite and same sex [2]. One of the important factors that underlie the turmoil in the family is the absence of one parent due to death or divorce. As a result, other family members should be able to find a way to adapt to the new situation in a way not to disturb the family functioning. Otherwise, family functioning faces trouble and the ground is provided for problems and abnormalities in the members [3]. In the mother-headed singleparent families, mothers need take the entire financial burden of the family, including their own and the children; as a result, the economic pressure causes the mothers to have less time to care for their children [1]. Recent surveys have shown that the quality of the relationship between parents and children is closely related to the behaviors of adolescents and their compatibility [4]. Parental monitoring suggests that parents be aware of how and with whom their children spend time, when they are not available. Beside, parents bear certain disciplinary practices and the children are expected not acting contrary to them, also they speak with the children about the acceptable behaviors and their examples, and if necessary provide information and guidance [5].Singleparent families, especially mother-headed ones have problems due to several problems including multiplicity of familial roles, lack of income, and shortage of awareness in administering family affairs and in controlling and monitoring the children behaviors[6-11]. Furthermore, among the challenges faced by single parents is the tendency towards high-risk behaviors among their adolescents [12-13]. High-risk behavior refers to any behavior that is harmful to one's mental and physical health [14]; High-risk behaviors such as smoking, alcohol and drug abuse, unsafe sexual behavior, suicide, and tendency to violence, and aggression that have been rising among adolescence in Iran in recent years [15]. Disruption of family structure, especially due to divorce, increases the likelihood of the high- risk behaviors by adolescents. Survey simply that the adolescents of single-parent families, in comparison with the adolescents of twoparent families, had less adjustment, and were more likely to abandon their education and to commit high-risk behaviors $[10,12,13]$.

Another challenge of single-parent families, in comparison to two-parent families, is the affiliation of their adolescents with delinquent peers, who spend a part of their time with delinquents [8]. Delinquent peers are the friends, who commit illegal and antisocial behaviors such as carrying weapons, harming others, participating in fight, and abusing of drugs and alcohol [16]. In another study, it was found that the family as well as delinquent peer group can have substantial impact on delinquency, so that delinquent peer group has a positive impact on increasing delinquency. however, the family plays role in reducing the impact of delinquent peer group and has a positive impact on reducing it [17]. Surveys show that children, who for various reasons (divorce or death) are headed by the mother, are more susceptible to the delinquent behaviors, and find themselves in small groups such as gangs and delinquent friends [8,18]. Moreover, a research has shown that affiliation with delinquent peers is caused by single-parent family of adolescents, and the separation from the mother leads to their criminal behavior [19]. It is clear that paying attention to this group of adolescents and revealing and solving their problems are not only essential for them and their families, but also they will be the further solutions for the social problems. Unfortunately, very few studies have been done in this area, and thus the lack of these studies and efforts to reduce and fix the problems are clearly visible in the personal and social damages on the adolescents. Given the importance of understanding the issues of the motherheaded single-parent families, the research saughtto answer this question that whether there is a difference among single-parent mother-headed adolescents and two-parent adolescents in terms of parental monitoring, 
affiliation with delinquent peers, and high-risk behaviors.

\section{Method}

This wasa causal-comparative study. The study population for the single-parent group was all the single-parent adolescents in Imam Khomeini Relief Foundation, Eslamabad-e Gharb,Iran. The population of the control group consisted of all high school students who lived with both parents. The sample in this study consisted of 100 single-parent male adolescents in Imam Khomeini Relief Foundation, Eslamabad-e Gharb County (Kermanshah Province), until August 2014. The participants were selected by convenience sampling method. All singleparent adolescents were mother-headed, and at least 5 years had passed of the absence of their father (for whatever reason). Single-parent adolescents aged between 15 and 19 years. To collect information from single-parent group, aftergetting permission from Imam Khomeini Relief Foundation of Eslamabad-e Gharb County. the adolescents and their families were informed about the study andthe questionnaires were distributed to the participants.

In addition, 100 two-parent adolescents, who were enrolled in the schools of Eslamabad-e Gharb County,were selected upon convenience sampling method and were matched based on age, gender, location, economic status, and academic grade of single-parent adolescents group;after reviewing the low economic situation of the majority of single-parent adolescents, for screening and matching the groups, those two-parent adolescents were selected who checked the middle and lower economic status of the demographic part of the questionnaires. In the two-parentadolescents group, both parentshad active participation in their lives, and there was no history of divorce and separation of the parents. In the present study, Parental monitoring questionnaire, Adolescent Affiliation with Deviant Peers Scale (AADPS), and Iranian Adolescents Risk Taking Scale (IARS) were used for data collection.

Parental monitoring questionnaire: parental monitoring was measured by Parental monitoring questionnaire created by Singer, Flannery, Guo, Miller, and Leibbrandtin 2004. Parental monitoring questionnaire has 7 questions. The subjects respond to it based on four point Likert scale. The lowest score is 0 and the highest is 3 for any question. The overall score indicates the amount of parental monitoring, and byscore increasing, parental monitoring is also increased. By a survey within the country, Cronbach's alpha was obtained 0.72 percent for the total scale [16]. In the present study, Cronbach's alpha coefficient for the total scale was 0.81 percent. Adolescent Affiliation with delinquent Peers questionnaire: This questionnaire was designed by Paschal, Ringwalt, Flewelling in 2003. It has 8 questions, which the subjects respond to each question based on a four point Likert scale, from grade 0 to grade 4. The total score of the questionnaire is consistent with the increase in affiliation of delinquent (deviant) peers. During a survey in Iran, Cronbach's alpha for the total scale was obtained 0.84 percent [16]. In the present study, Cronbach's alpha coefficient for the total scale was obtained 0.88 percent.

Iranian Adolescents Risk Taking scale: This scale was designed by Zadeh Mohammadi et al. It has 38 questions, which assesses the vulnerability of adolescents in highrisk behaviors such as dangerous driving, propensity to violence, smoking, taking drugs and psychotropic substances, tendency to the opposite sex, and sexual relationships and behavior. The lowest grade is 1 and the highest grade is 5 in the scale, so that increasing scores represent an increase in high-risk behaviors. Duringa domestic survey, Cronbach's alpha for the total scale was obtained 0.93 percent [20]. In the present study, Cronbach's alpha coefficient for the total scale was 0.89 percent. The collected data anaylysed by SPSS- 18 and running multivariate analysis of variance (MANOVA).

\section{Results}

The sample group consisted of 100 twoparent adolescents, and 100 mother-headed 
single-parent adolescents. Among the total 100 single-parent adolescents, five subjects were excluded due to incomplete responseto the questionnaires. The minimum and maximum age of participants was 15 and 19 years old. The mean and standard deviation of the age variable were $17.23 \pm 0.76$, and $16.89 \pm 1.44$ for single-parentandcontrol groups, respectively. Descriptive statistics of the dependent variables, including mean and standard deviation in both control and singleparentgroupsare presented in Table 1.

Table 1 Frequently distribution of some of the characteristics of participants

\begin{tabular}{lcccc}
\hline \multicolumn{2}{c}{$\begin{array}{c}\text { Demographic } \\
\text { characteristics }\end{array}$} & $\begin{array}{c}\text { Group of single-parent } \\
\mathrm{N}(\%)\end{array}$ & $\begin{array}{c}\text { normal group } \\
\mathrm{N}(\%)\end{array}$ & $\begin{array}{c}\text { The amount of P } \\
\text { Chi-square test }\end{array}$ \\
\hline \multirow{2}{*}{ Age } & $15-17$ & $66(69.47)$ & $70(70)$ & $\begin{array}{c}\mathrm{P}=0.01 \\
\mathrm{Df}=2\end{array}$ \\
& $17-19$ & $29(30.52)$ & $30(30)$ & \begin{tabular}{c} 
Chi-square $=9.35$ \\
\hline $\begin{array}{l}\text { The economic } \\
\text { situation }\end{array}$
\end{tabular} \\
\hline
\end{tabular}

The results of Table 1 indicate two features of the demographic variables. The results were analyzed with $\mathrm{X}^{2}$ test. According to the results of the test, our participants were homogenous in

terms of demographic differences representing the community. In other words, the assignment of participants was homogeneous in experimental and control groups.

Table 2 Descriptive dates in two variables

\begin{tabular}{lcccc}
\hline Variables & Groups & Frequency & $\mathrm{M}$ & $\mathrm{SD}$ \\
\hline \multirow{2}{*}{ Parental monitoring } & Single parent & 95 & 12.55 & 4.19 \\
& Normal & 100 & 16.54 & 4.18 \\
\hline \multirow{2}{*}{ Affiliation with } & Single parent & 95 & 7.35 & 4.33 \\
delinquent peers & Normal & 100 & 5.25 & 5.01 \\
\hline \multirow{2}{*}{ High-risk behaviors } & Single parent & 95 & 74.44 & 20.10 \\
& Normal & 100 & 70.62 & 26.17 \\
\hline
\end{tabular}

Kolmogorov-Smirnov $\mathrm{z}$ statistic for the variables was not significant (at $\mathrm{p}<0.05$ level), i.e. the distribution of the variables among sample was consistent with its distribution in the population. In the Levene's test, Fstatistic for variables is not significant $(p<0.05)$ manifesting that the error variance of the variables was different among the participants (both groups).

To test the hypotheses, multivariate analysis of variance (MANOVA) was used. Table 3 indicates that all the tests showed a significant difference between the groups. This means that there was a significant difference at least in one of the compared variables of singleparent and two-parent groups.

Table 3 The results of multivariate analysis of variance

\begin{tabular}{lccccc}
\hline & Value & F & Hypothesis df & Error df & Sig \\
\hline Pillai's Trace & 0.15 & 9.13 & 3.00 & 154.00 & 0.00 \\
Wilks' Lambda & 0.70 & 9.13 & 3.00 & 154.00 & 0.00 \\
Hotelling's Trace & 0.42 & 9.13 & 3.00 & 154.00 & 0.00 \\
Roy's Largest Root & 0.42 & 9.13 & 3.00 & 154.00 & 0.00 \\
\hline
\end{tabular}

Table 4 The results of analysis of variance to compare variables between the two groups.

\begin{tabular}{llccccc}
\hline Source of changes & Variables & Ss & Df & Ms & F & Sig \\
\hline \multirow{4}{*}{ Group } & Parental monitoring & 119.21 & 1 & 119.21 & 0.21 & 0.00 \\
& Affiliation with delinquent peers & 142.76 & 1 & 142.76 & 6.43 & 0.00 \\
& High-risk behaviors & 348.62 & 1 & 348.62 & 19.87 & 0.00 \\
\hline
\end{tabular}


In Table 4, the results of multivariate analysis of variance are shown comparing the dependent variables of both groups $(p<0.05)$. It can be concluded that the single-parent group, in comparison to the two-parent group, a cored higher at affiliation with delinquent peers $(\mathrm{f}=$ 0.21 ), and high-risk behaviors ( $\mathrm{f}=6.43$ ), and scored lower in terms of parental monitoring $(f=19.87)$.

\section{Discussion}

The present study aimed to investigate singleparent and two-parent adolescents regarding parental monitoring, affiliation with delinquent peers, and high-risk behaviors. The research findings indicated that the level of parental monitoring is lower in single-parent adolescents compared to two-parent adolescents. On the other hand, the possibility of a tendency toward delinquent peers and engagement in high-risk behaviors were higher among them.

In a more detailed analysis, reviewing the parental monitoring showed that the singleparent adolescents (mother-headed) were at a lower level in comparison to the two-parent adolescents. The results were consistent with the studies of Schumacher [6] and Dehghani et al [11]. Based on these investigations, singleparent adolescents are at a lower level in terms of parental monitoring compared to twoparent adolescents that can be attributed to the absence of one of the parents. The functions and responsibilities of the other parent must be changed in a way to be able to compensate for the necessity. If this process does not happen properly, parental functions and responsibilities become weak and chaotic. The absence of father, on the one hand, creates emotional vacuum; not to filling the gap through family supporting system, a person looks for replacement. On the other hand, this leads to a lack of adequate monitoring of the children's behavior and cause them to leave their psychosocial development mainstream. Living in a single-parent family imports more pressure on both the parent and the child, and the pressure becomes intense when the parent's social and economic situation is unsatisfactory. In families where the mother is the only parent and family economic status is low, often the most of time and energy of the parent are spent in order to meet the financial and economic needs of the children, and she becomes incapable in dealing with the other parental responsibilities and education of the children. As a result, the movement towards the areas of inefficiencies and anomalies is facilitated in the offspring. So, it seems logical that the single-parent adolescents experience lower levels of parental monitoring comparing to two-parent peers.

Checking the status of affiliation with delinquent peers indicated that single-parent adolescents spend more time with delinquent peers than two-parent adolescents. The findings of this study can be aligned with the findings of Eitel [8] and Paschal [19]. The adolescents of single-parent families are more susceptible to the affiliation of delinquent peers than two-parent families, because the absence of parents exerts itself through the lack of adequate monitoring of the adolescents. Improper performance of parental duties is among the obvious factors, which can associate with deviant peers and accelerates the engagement in high-risk behaviors in adolescents [6]. It is clear that emotional bond with parents can prevent the adolescent involvement in harmful and inefficient behaviors. Parents, who take the burden of the family alone, for various reasons, have less opportunity to create an emotional bond and deep relationship with their children. The same agent can decrease the interaction of the child with the parent. Less emotional attachment to family leads to the decrease of internalization of norms and traditional practices for the adolescents, which in turn causes adolescents to socialize and develop relationships with peer groups and various unfamiliar, and abnormal social networks that tend to be drawn to high-risk and traumatic behaviors [21-22].

In relation to the status of high-risk behaviors, thestudy showed thatsingle-parentadolescents possess less adjustment compared to twoparent adolescents, and therefore are more 
inclined to high-risk behaviors. The findings of this study can be consistent with previous results of Hemovich and crano [12] and Clark et al [13]. To explain these findings, it can be confirmed that among the variables affecting the family, the lack of parental monitoring is one of the main causes of the high-risk behaviors in adolescents [24]. On the other hand, the lack of adequate monitoring of children is an important factor in accelerating the affiliation of delinquent peers and high-risk behaviors in adolescents [6]. An adolescent, who lives in a discrete family and has a weak parental bond and does not receive the necessary support and attention in the family environment at the same time, is dragged towards the outside of the house, and his relationships with peers and largely unfamiliar social networks becomes very important. Affiliation and identification of the adolescents with their peers or dependence to them, regardless of socioeconomic class, are seen as a key factor in high-risk behaviors $[25,26]$.

The nature and quality of communication with deviant peers is a crucial indicator of adolescents' social deviant behavior patterns. As a result, the affiliation with delinquent peers is a strong predictor of the incidence of highrisk behaviors. So, it can be concluded that poor parental monitoring in the single-parent families spreads the possibility of relationship and association with deviant and delinquent peers. Consequently, these two factors increase the tendency and context to perform a variety of high-risk behaviors in adolescents.

Non-comparability between male and female single-parent adolescents, the exclusiveness of the results for Eslamabad-e Gharb County (Kermanshah Province), and the lack of generalized ability were of the major limitations of the study.

\section{Conclusion}

This research results showed that the vulnerability of single-parent adolescents is consistent with low parental monitoring and high affiliation with deviant peers. On the other hand, the increase of the likelihood of high-risk behaviors by single-parent adolescents can cause serious attention to these vulnerable families and adolescents. Therefore, prevention programs are required to pay more attention to the role of family in social and behavioral problems in singleparent adolescents.

\section{Acknowledgements}

Those who helped the author(s) in this study, especially the adolescents, are respected and appreciated.

\section{Contribution}

Study design: ShD, ARSh, JKhS, MN, ZB

Data collection and analysis: $\mathrm{ShD}$, ARSh, JKhS, MN, ZB

Manuscript preparation: ShD, ARSh, JKhS, MN, ZB

\section{Conflict of Interest}

"The authors declare that they have no competing interests."

\section{Funding}

The author (s) received no financial support for the research, authorship and/or publication of this article.

\section{References}

1- Hamidi F. Relationship between social support and mental health among female-headed households employed a military university. Journal of Military Psychology2010; 1(2): 51-60.

2- Glading S. Family therapy, history and practice. 1st ed. Translated by Bahari F, et al. Tehran: Tazkie publication; 2008.

3- Kotwal N, Prabhakar B. Problems faced by single mothers. J Soc Sci2009; 21(3): 197-204.

4- Allison BN, Schultz JB. Parent-adolescent conflict in early adolescence. Adolescence2004; 39(153): 101-19.

5- Romero AJ, Ruiz M. Does familism lead to increased parental monitoring? Protective factors for coping with risky behaviors. J Child Fam Stud2007; 16(2): 143-54. 6- Shoemaker DJ. Theories of delinquency: an examination of explanations of delinquent behavior. 6th Ed. New York: Oxford university press; 2010.

7- Frojd S, Kaltiala-Heino R, Rimpela M. The association ofparental monitoring and family structure with diversemaladjustment outcomes in middle 
adolescent boysandgirls. Nord J Psychiatry2007; 61(4): 296-303.

8- Eitle D. Parental gender, single-parentfamilies, and delinquency: Exploring the moderatinginfluenceofrace/ ethnicity. Soc Sci Res2006; 35: 727-48.

9-Zimmermann G. Delinquency in male adolescents: The role of Alexithymia and family structure. J Adolesc2006; 29(3): 321-32.

10- Demuth S, Brown SL. Familystructure, family processes, and adolescentdelinquency: the significance of parental absenceversus parental gender. $J$ Res Crime Delinq2004; 41(1): 58-81.

11-Dehghani M, Roushan M, Ganjavi A. An investigation on insufficient forensic psychology assessment of juveniles in correction service center. Journal of Family Research2008; 4(14): 167-78.

12- Hemovich V, Crano W. Family structure and adolescent drug use: An exploration of single-parent families. Subst Use Misuse2009; 44(14): 2099-113.

13- Clark JJ, Sawyer MG, Nguyen AM, Baghurst PA. Emotional and behavioral problems experienced by children living in single-parent families: a pilot study. $J$ Paediatr Child Health1993; 29(5): 338-43.

14- Swahn MH, Bossarte RM. Assessing and quantifying high risk: Comparing risky behaviors by youth in an urban, disadvantaged community with nationally representative youth. Public Health Rep2009; 124(2): 224-33.

15- Zadeh Mohammadi A, Ahmadabadi Z, Heidari M. Construction and assessment of psychometric features of Iranian adolescents risk-taking scale. Iranian Journal of Psychiatry and Clinical Psychology2011; 17(3): 218-25.

16- Nazari AM, Aminimanesh S, Shahini A. Family structure, parental monitoring and affiliation with delinquent peers in male adolescent delinquent and normal. Research in Psychological Health2013; 6(4): 60- 8.

17- Gao Y, Yu Y, Kin NT. A study of the moderating effect of family functioning on the relationship between deviant peer affiliation and delinquency among Chinese adolescents. Adv Appl Sociol2013; 3(3): 178- 85.

18- Charles MB, Scott WH. Post-divorce mother-son relations of delinquent and well-adjusted adolescents. J Appl Dev Psychol1987; 8(3): 273-88.

19- Paschal MJ, Ringwalt CL, Flewelling RL. Effects ofparenting, father absence, and affiliation with delinquent peers on delinquent behavior among African-American male adolescents. Adolescence2003; 38(149): 15-34.

20- Zadeh Mohammadi A, Ahmad Abadi Z. The co-occurrence of risky behaviors among high school adolescents in Tehran. Journal of Family Research2008; 4(1); 87-100.

21- Ahmadi K, Khodadadi Sangdeh J, Aminimanesh S, Mollazamani A, Khanzade M. The role of parental monitoring and affiliation with deviant peers in adolescents' sexual risk taking: toward an interactional model. Int J High Risk Behav Addict2013; 2(1): 22- 7. 22- Kumpfer, KL, Alvarado R, Tait C, Turner C. Effectivenessof school-based family and children's skills training for substance abuseprevention among 8-6 year old rural children. Psychol Addict Behav2002; 16(4): S65-S71.

23- Mohamadkhani SH. Structural model of alcohol, and other drugs among at risk adolescents: direct and indirect impact of social and personal factors. Research in Psychological Health2007; 1(2): 5-16.

24- Singer MI, Flannery DJ, Guo S, Miller D, Leibbrandt S. Exposure to violence, parental monitoring, and television viewing as contributors to children's psychological trauma. J Community Psychol2004; 32(5): 489-504.

25- Lansford JE, Dodge KA, Fontaine RG, Bates JE, Pettit GS. Peer rejection, affiliation with deviant peers, delinquency, and risky sexual behavior. $J$ Youth Adolesc2014; 43(10): 1742-51.

26- Engels Rutger CME, Ter Bogt T. Influences of risk behaviors on the quality of peer relations in adolescence. J Youth Adolesc2001; 30(6): 675-95.

\footnotetext{
Copyright $\subset 2016$ ASP Ins. This open-access article is published under the terms of the Creative Commons Attribution-NonCommercial 4.0 International License which permits Share (copy and redistribute the material in any medium or format) and Adapt (remix, transform, and build upon the material) under the Attribution-NonCommercial terms.
} 